\title{
CONSUMO DE ÁGUA PELA CULTURA do CRISÂNTEMO CULTIVADA EM AMBIENTE PROTEGIDO ${ }^{1}$
}

\author{
JOELMA R. D. PEREIRA ${ }^{2}$, JACINTO DE A. CARVALHO ${ }^{3}$, DOUGLAS S. MIGUEL ${ }^{4}$, \\ MÁRCIO J. DE SANTANA ${ }^{5}$
}

\begin{abstract}
RESUMO: Com o objetivo de determinar o consumo de água pela cultura do crisântemo, ao longo do seu ciclo de desenvolvimento, conduziu-se um experimento em ambiente protegido, na Universidade Federal de Lavras - MG, com as cultivares Kátia e Bi Time. O delineamento experimental foi o inteiramente casualizado, em esquema fatorial, com duas cultivares e duas freqüências de irrigação, com oito repetições, sendo o manejo da irrigação feito utilizando-se do método da pesagem. $\mathrm{O}$ consumo de água entre irrigações foi obtido pela pesagem dos vasos. Instalou-se na área experimental um tanque Classe A, para obter a evaporação e posterior correlação com o consumo hídrico das cultivares. Verificou-se que não houve diferença significativa do consumo quando as cultivares foram irrigadas uma e duas vezes ao dia. Observou-se que as cultivares possuem consumo diferenciado segundo seus estádios de desenvolvimento. O consumo médio de água, ao longo do ciclo, para a freqüência de irrigação de uma e duas vezes ao dia, da cultivar Kátia, foi de 118 e $108 \mathrm{~mL} \mathrm{dia}^{-1}$, e da cultivar Bi Time, foi de 98 e $113 \mathrm{~mL} \mathrm{dia}^{-1}$, respectivamente.
\end{abstract}

PALAVRAS-CHAVE: manejo da irrigação, necessidade hídrica, Dendranthema grandiflora.

\section{WATER REQUIREMENT BY CHRYSANTHEMUM CULTIVATED UNDER GREENHOUSE CONDITIONS}

\begin{abstract}
With the objective of determining the chrysanthemum water consumption, an experiment was carried out at the Universidade Federal de Lavras, MG, Brazil, under greenhouse condition, with two chrysanthemums cultivars, Kátia and $\mathrm{Bi}$ Time. A completely randomized experimental design in a factorial outline, with eight replications, two cultivars and two irrigation frequencies were used. Irrigation scheduling was based on pot plant weight. The water consumption between irrigations was obtained by weighting the pot. A class A tank, was used to obtain the evaporation and subsequent correlation with the crop water consumption. It was verified that there was not significant difference of water requirement when the cultivars were irrigated once and twice day. It was observed that the cultivars presented differentiated water requirement according to the development stage. Along the cycle, the average water consumption, for once and twice day irrigation, for cultivar Kátia was 118 and $108 \mathrm{~mL} \mathrm{day}^{-1}$ and for the cultivar Bi Time was 98 and $113 \mathrm{~mL} \mathrm{day}^{-1}$, respectively.
\end{abstract}

KEYWORDS: water management, water requirement, Dendranthema grandiflora.

\section{INTRODUÇÃO}

Para o manejo adequado da água de irrigação, é necessário o controle da umidade do solo e/ou da evapotranspiração durante todo o ciclo da cultura. Para tanto, é indispensável o conhecimento de

\footnotetext{
${ }^{1}$ Projeto financiado pela FAPEMIG.

${ }^{2}$ Eng ${ }^{a}$ Agrícola, Doutoranda em Irrigação e Drenagem, DEG, UFLA, Lavras - MG, Fone: (0XX35) 3829.1384, jodurao@ terra.com.br

${ }^{3}$ Eng $^{-}$Agrícola, Prof. Adjunto, Departamento de Engenharia, Lavras - MG. Bolsista CNPq.

${ }^{4}$ Graduando Agronomia, Departamento de Engenharia, Lavras - MG. Bolsista PIBIC-CNPq.

${ }^{5}$ Eng ${ }^{0}$ Agrônomo, Doutorando em Irrigação e Drenagem, Departamento de Engenharia, Lavras - MG.

Recebido pelo Conselho Editorial em: 24-6-2003

Aprovado pelo Conselho Editorial em: 29-8-2005
} 
parâmetros relacionados às plantas, ao solo e ao clima, para determinar o momento oportuno de irrigar e a quantidade de água a ser aplicada (SILVA \& MAROUELLI, 1998).

Muitas pesquisas sobre a necessidade de água têm sido realizadas para as grandes culturas. Entretanto, para as culturas desenvolvidas sob ambiente protegido, a pesquisa está defasada em relação a outros países, principalmente no setor de floricultura (CASARINI, 2000).

O consumo de água pelo crisântemo e pelas plantas ornamentais é, no geral, pouco estudado, sendo a literatura a respeito praticamente inexistente. Desse modo, nota-se que há certa dificuldade por parte dos produtores em fazer o manejo racional da irrigação nessas culturas, principalmente naquelas conduzidas em ambiente protegido, visto que, por apresentarem condições ambientais próprias, impedem o uso direto dos métodos já consagrados para a determinação da evapotranspiração (FURLAN, 1996). Diversos trabalhos de pesquisas realizados em outros países mostram que o consumo hídrico de espécies cultivadas em ambientes protegidos é 20 a $40 \%$ inferior em relação ao cultivo a céu aberto (MARTINS et al. 1999).

A cultura do crisântemo, desenvolvida em vasos, necessita de grande quantidade de água e fertilizantes. Para cada tamanho de vaso ou pote, são recomendadas quantidades diferentes de água, em função da evapotranspiração das plantas. Esse controle é essencial para o bom desenvolvimento das plantas e para evitar desperdícios. Esses autores descrevem uma forma simples de aplicação de água na cultura de acordo com o tamanho do vaso ou pote. Essas regas são feitas vaso a vaso e com freqüência de três a quatro vezes ao dia, em média.

O correto manejo da irrigação, para obtenção de produtividade viável economicamente, seria aquele em que se aplica água no solo, no momento oportuno e em quantidades suficientes para suprir as necessidades hídricas da cultura, sem falta ou desperdício de energia. Para que isso ocorra, há a necessidade do uso de métodos de campo que determinem, direta ou indiretamente, a disponibilidade de água no solo para uma determinada cultura (VILLA NOVA, 1991).

Baseando-se nisso, este trabalho teve como objetivo avaliar o efeito da freqüência de irrigação em duas cultivares de crisântemo, assim como o consumo de água pela cultivar ao longo do seu ciclo de desenvolvimento.

\section{MATERIAL E MÉTODOS}

O experimento foi conduzido no Laboratório de Hidráulica da Universidade Federal de Lavras (UFLA), no município de Lavras - MG, em estufa modelo arco, tendo como material de cobertura polietileno de baixa densidade, de 150 micras, transparente, apresentando pé-direito de 3,5 $\mathrm{m}$, com janelas na sua estrutura, em forma de arco, propiciando assim ventilação da casa de vegetação. $\mathrm{O}$ experimento foi realizado no período de agosto a dezembro de 2002. Lavras está situada no sul de

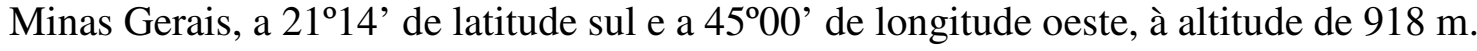

A espécie utilizada neste estudo foi a Dendranthema grandiflora, sendo os estudos feitos com as cultivares Kátia e Bi Time. São cultivares consideradas minicrisântemos, para produção em vasos, sendo a cultivar Kátia pertencente ao grupo de variedades Gardini, com inflorescências de cor branca, e a cultivar Bi Time pertence ao grupo Girassol, com inflorescências de cor rosa-clara.

Foram utilizados vasos de polietileno, comercialmente denominados pote $\mathrm{n}^{\mathbf{0}} 11$, que possuem volume de $1,3 \mathrm{dm}^{3}$. A densidade de plantio foi de 10 vasos por $\mathrm{m}^{2}$, sendo esses preenchidos com substrato comercial Rendimax, recomendado para a cultura do crisântemo. Foram adicionados 3,35 g de calcário dolomítico calcinado e micropulverizado em cada vaso, 30 dias antes do transplantio das mudas, elevando-se a saturação de bases de $52,9 \%$ para $70 \%$. 
$\mathrm{O}$ experimento foi instalado em delineamento inteiramente casualizado, em esquema fatorial 2 x 2, sendo: duas cultivares (Kátia e Bi Time) e duas freqüências de irrigação (1 e 2 vezes ao dia), com oito repetições, sendo o croqui do experimento apresentado na Figura 1. Os tratamentos tiveram início aos 23 dias após o transplantio das mudas.

Os vasos com as plantas foram dispostos em cinco fileiras duplas, contendo cada uma 12 vasos, num total de 120 (Figura 1). As fileiras externas, bem como os dois primeiros e os dois últimos vasos de cada fileira, foram destinados à bordadura. Os vasos foram colocados em cima de tijolos, a uma altura de $0,10 \mathrm{~m}$ do chão.

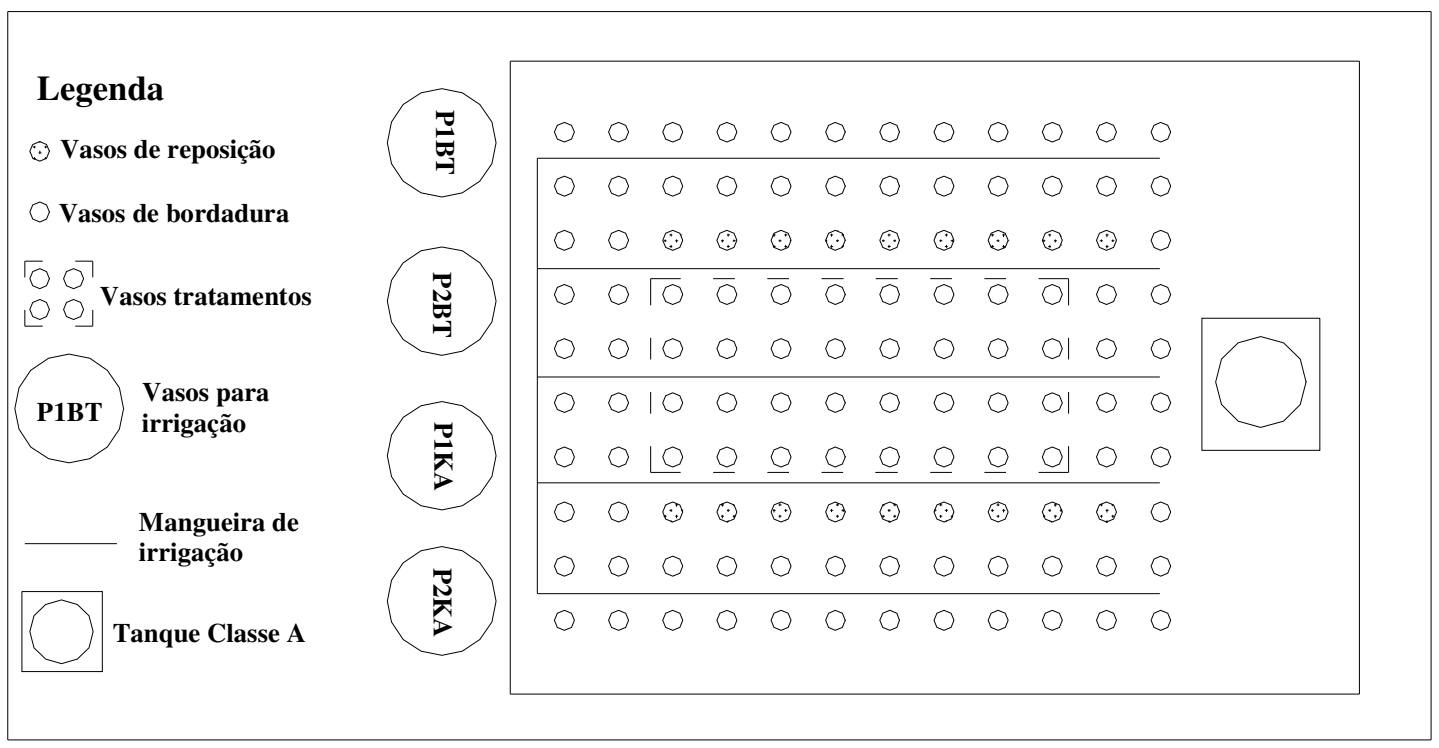

P1BT e P2BT - irrigação uma e duas vezes ao dia, respectivamente, para cultivar Bi Time; P1KA e P2KA - irrigação uma e duas vezes ao dia, respectivamente, para cultivar Kátia.

FIGURA 1. Croqui representativo da área experimental.

Fez-se a aplicação dos adubos via água de irrigação, conforme apresentado na Tabela 1.

TABELA 1. Quantidade de adubos utilizados para a cultura do crisântemo em vaso, para cada 1.000 L de água.

\begin{tabular}{cc}
\hline Adubos & Quantidades $\left(\mathrm{g} 1000 \mathrm{~L}^{-1}\right)$ \\
\hline Nitrato de amônio & 400 \\
Nitrato de cálcio & 800 \\
Nitrato de potássio & 800 \\
Sulfato de magnésio & 600 \\
MAP (Fosfato monoamônico) & 150 \\
\hline
\end{tabular}

Fonte: Agnaldo Lio, Veiling Holambra, informação pessoal.

A irrigação foi feita duas vezes ao dia, sendo a primeira às $8 \mathrm{~h}$, em todos os vasos, e a segunda às $16 \mathrm{~h}$, nos vasos que pertenciam ao tratamento com frequiência de irrigação de duas vezes ao dia. Utilizou-se de um sistema de irrigação localizada, por gravidade, para a condução do experimento. A água e a solução eram distribuídas aos vasos por tubos de polietileno de diâmetro $13 \mathrm{~mm}$ (1/2"), aos quais foram conectados microtubos com gotejadores da marca Netafim, com vazão de $2,5 \mathrm{~L} \mathrm{~h}^{-1}$. O sistema apresentou coeficiente de uniformidade de Christiansen (CUC) de $95 \%$. 
De acordo com a recomendação de PEREIRA (2002), a reposição da água de irrigação foi feita de forma integral (reposição de 100\% da água consumida pela cultura).

O controle da irrigação foi feito utilizando-se do método da pesagem. Inicialmente, pesaram-se os vasos na condição de capacidade de campo. Contudo, a capacidade de campo foi determinada em laboratório, utilizando três vasos idênticos aos utilizados no experimento. O substrato foi saturado com água e coberto com um saco plástico para evitar a evaporação. Foi monitorada a variação do peso dos vasos. Quando esses atingiram peso constante, teve-se, então, o peso que correspondia à capacidade de campo.

Antes de cada irrigação, pelo menos três vasos correspondentes a cada cultivar eram pesados e a diferença entre o peso atual e aquele correspondente à capacidade de campo correspondia ao peso (volume) da água de reposição.

A cada 15 dias, foi obtido o peso médio de uma planta de cada tratamento. Para isso, foram utilizadas plantas de três vasos em cada uma das medições. Para cada cultivar, foram cultivados nove vasos extras, os quais eram destinados à obtenção do peso da planta. O peso, assim obtido, era considerado no cálculo do volume da água de irrigação.

Com o objetivo de determinar uma forma prática para o manejo da irrigação da cultura, correlacionaram-se os dados do tanque Classe A e do consumo hídrico de cada cultivar. Dessa forma, gerou-se um coeficiente relativo (CR), obtido de acordo com a seguinte expressão:

$$
\mathrm{CR}=\frac{\text { Consumo Diário }(\mathrm{mL})}{\text { Evaporação Diária }(\mathrm{mm})}
$$

O consumo foi dividido de acordo com as fases de desenvolvimento do crisântemo: vegetativa (PEREIRA, 2002). A fase vegetativa, para a cultivar Kátia, compreendeu o período entre o transplantio e o $42^{\circ}$ dia após o transplantio (DAT); a fase de florescimento entre o $43^{\circ}$ DAT até a colheita. No entanto, para melhor observação, dividiu-se essa fase em três períodos de consumo: $43^{\circ}$

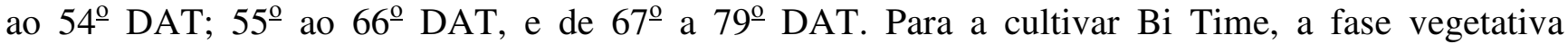
compreendeu o período entre o transplantio e o $46^{\circ}$ DAT; a fase de florescimento entre o $47^{\circ}$ DAT e a colheita. Da mesma forma que a análise feita para a cultivar Kátia, dividiu-se essa fase em três períodos de consumo: $47^{\circ}$ ao $58^{\circ}$ DAT; $59^{\circ}$ ao $70^{\circ}$ DAT, e de $71^{\circ}$ a $79^{\circ}$ DAT.

O crisântemo é uma planta de dias curtos, necessitando de fotoperíodo longo na fase vegetativa. Utilizou-se do controle artificial de iluminação ao longo do ciclo da cultura, com o fornecimento de iluminação por meio de lâmpadas incandescentes e diminuição do fotoperíodo, conforme a época e o estágio da cultura, de acordo com GRUSZYSNKI (2000).

Para estimular o surgimento de brotações laterais, realizou-se o "pinch", retirando-se o ponteiro central das plantas quando as mesmas apresentavam de quatro a seis folhas.

A colheita foi determinada quando $50 \%$ ou mais dos vasos correspondentes a cada cultivar apresentaram $50 \%$ ou mais das inflorescências abertas.

No final do experimento, avaliou-se a qualidade do produto final pela classificação dos vasos de crisântemo, segundo o padrão do Instituto Brasileiro de Floricultura (IBRAFLOR) (MOTOS, 2000).

As análises de variância do experimento foram feitas de acordo com o pacote estatístico SISVAR, versão 4.3, desenvolvido por FERREIRA (1999).

\section{RESULTADOS E DISCUSSÃO}

De acordo com os resultados da análise de variância, não houve diferenças significativas entre as freqüências de irrigação e cultivares estudadas, para a característica qualidade do produto final (Tabela 2). 
O consumo de água das cultivares Kátia e $\mathrm{Bi}$ Time foi monitorado durante todo o ciclo de desenvolvimento da cultura (Figuras 2 e 3).

TABELA 2. Análise de variância representada pelo Quadradro Médio (Q.M.).

\begin{tabular}{lcc}
\hline \multirow{2}{*}{ Fontes de Variação } & Graus de Liberdade & Q.M. \\
\cline { 3 - 3 } & & Classes de Qualidade \\
Cultivar & 1 & $0,0625 \mathrm{~ns}$ \\
Freqüência de irrigação & 1 & $0,593 \mathrm{~ns}$ \\
Cultivar x freqüência & 1 & $0,0625 \mathrm{~ns}$ \\
Resíduo & 12 & 0,396 \\
\hline C.V. $(\%)$ & 23,41 & \\
\hline
\end{tabular}

ns: não significativo a 5\% de probabilidade.

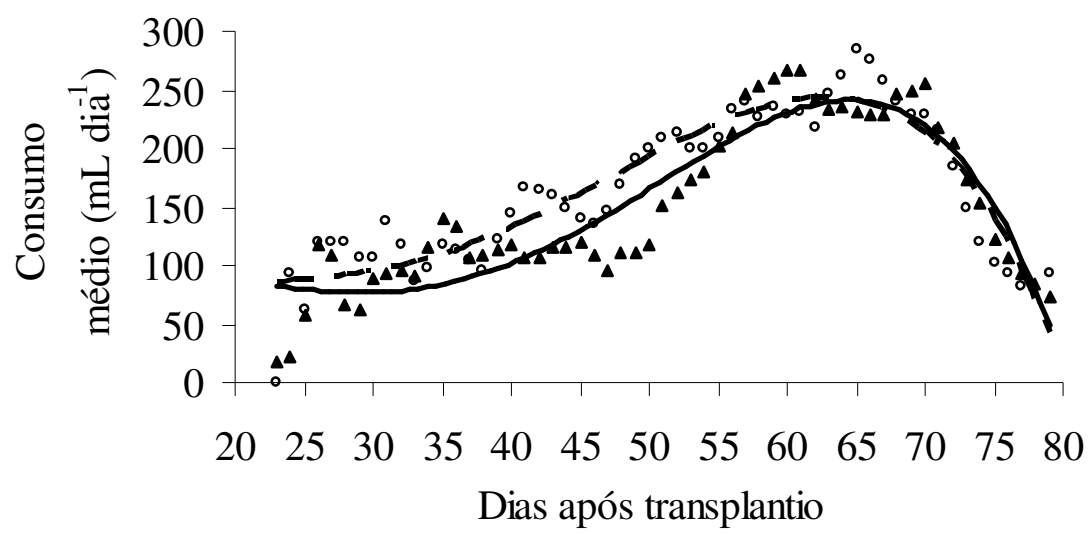

FIGURA 2. Consumo médio diário de água pela cultura do crisântemo cv. Kátia, ao longo do ciclo de desenvolvimento, de acordo com a freqüência de irrigação.

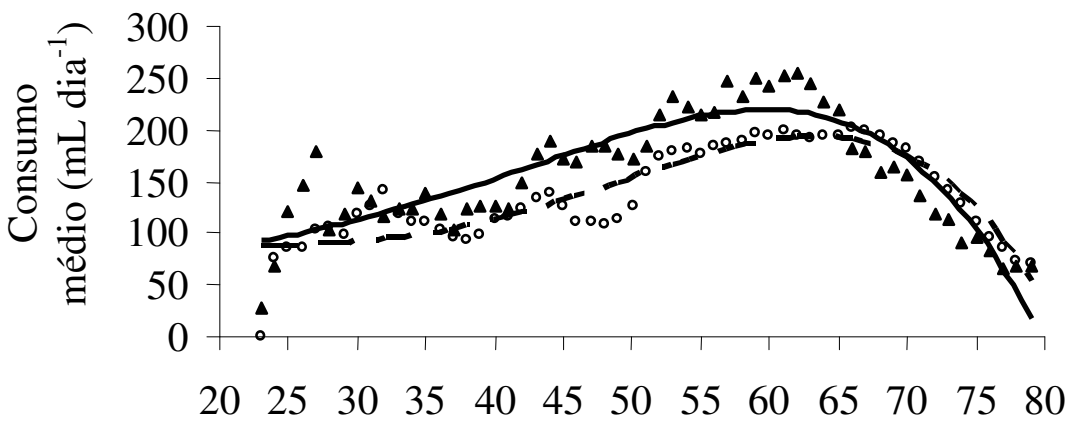

Dias após transplantio

$$
\text { … Irrigação Diária } \triangle 2 \text { Irrigações Diárias }
$$

FIGURA 3. Consumo médio diário de água pela cultura do crisântemo cv. Bi Time, ao longo do ciclo de desenvolvimento, de acordo com a freqüência de irrigação. 
Observa-se que, para as cultivares estudadas, em ambas as frequiências de irrigação, o consumo de água é crescente, atingindo valores máximos, para a cultivar Kátia, próximo aos 65 DAT (Figura 2), enquanto, para a cultivar Bi Time, esses valores encontram-se próximos aos 60 DAT (Figura 3). A partir desses pontos, há redução do consumo até a colheita. Os pontos de pico, fase de maior demanda hídrica da cultura, correspondem à fase da formação e abertura das inflorescências.

Para a cultivar Kátia (Figura 2), observa-se que há ligeiro aumento do consumo para a frequiência de irrigação de uma vez ao dia, não diferindo, entretanto, estatisticamente daquele apresentado com maior freqüência. Irrigando-se uma vez ao dia, aplicavam-se maiores volumes de água, resultando em maior volume de percolação, quando comparado com a freqüência de duas vezes ao dia. Isso era devido, em parte, à grande porosidade do substrato. Com isso, as necessidades hídricas da cultivar não foram totalmente supridas, apesar da reposição integral de água, havendo, dessa forma, secamento parcial do substrato.

Da mesma forma, para a cultivar Bi Time (Figura 3), as freqüências de irrigação não influenciaram significativamente no consumo. No entanto, houve ligeiro aumento do consumo quando as plantas foram irrigadas duas vezes ao dia, não havendo, também, diferença estatisticamente. Essa diferença no consumo, provavelmente, mostra maior sensibilidade dessa cultivar à aplicação de água. Uma irrigação mais frequiente mantém a umidade mais alta por mais tempo, favorecendo a evaporação e facilitando a retirada de água pelas plantas, com conseqüente aumento da transpiração das plantas, acarretando, assim, maior consumo hídrico pela cultura.

Pela Tabela 3, tem-se o consumo médio de água pela cultivar Kátia, de acordo com os períodos analisados.

TABELA 3. Consumo médio de água pela cultura do crisântemo, cv. Kátia, ao longo do ciclo de desenvolvimento, de acordo com a freqüência de irrigação.

\begin{tabular}{|c|c|c|c|}
\hline $\begin{array}{c}\text { Estágios de } \\
\text { Desenvolvimento }\end{array}$ & DAT & Freqüêencia de Irrigação & Consumo Médio de Água (mL dia $\left.{ }^{-1}\right)$ \\
\hline \multirow{2}{*}{ Vegetativa } & \multirow{2}{*}{$\begin{array}{c}\text { Transplantio } \\
\text { até } 42\end{array}$} & $1 \mathrm{vez}$ ao dia & 52 \\
\hline & & 2 vezes ao dia & 44 \\
\hline \multirow{6}{*}{ Florescimento } & \multirow{2}{*}{43 a 54} & $1 \mathrm{vez}$ ao dia & 176 \\
\hline & & 2 vezes ao dia & 130 \\
\hline & \multirow{2}{*}{55 a 66} & 1 vez ao dia & 241 \\
\hline & & 2 vezes ao dia & 240 \\
\hline & \multirow{2}{*}{67 a 79} & 1 vez ao dia & 160 \\
\hline & & 2 vezes ao dia & 170 \\
\hline \multirow{2}{*}{\multicolumn{2}{|c|}{ Consumo Médio do Ciclo }} & 1 vez ao dia & 118 \\
\hline & & 2 vezes ao dia & 108 \\
\hline
\end{tabular}

Pela Tabela 4, tem-se o consumo médio de água pela cultivar Bi Time, de acordo com as fases analisadas.

O consumo médio ao longo do ciclo, para ambas as cultivares e freqüências de irrigação, está de acordo com os valores observados por MOTOS \& OLIVEIRA (1990), ou seja, entre 70 a $120 \mathrm{~mL} \mathrm{dia}^{-1}$ para plantas cultivadas em potes $\mathrm{n}^{\mathrm{o}}$ 11. No entanto, é importante observar que esse consumo não é constante. Durante a fase vegetativa, o consumo médio de água, para as cultivares Kátia e Bi Time, para freqüências de duas vezes ao dia, foi de 44 e $68 \mathrm{~mL} \mathrm{dia}^{-1}$, respectivamente. PEREIRA (2002), observando o consumo de água pelo crisântemo, cultivar White Diamond, verificou também que o consumo não é constante ao longo do ciclo da cultura. O consumo médio, para todo o ciclo, foi de 
$83 \mathrm{~mL} \mathrm{dia}^{-1}$, para plantas cultivadas em potes $\mathrm{n}^{\mathrm{o}} 11$. Durante a fase vegetativa, o consumo médio de água foi de $33 \mathrm{~mL} \mathrm{dia}^{-1}$. A fase de florescimento foi dividida em três etapas: $43^{\circ}$ até $62^{\circ}$; $63^{\circ}$ até $82^{\circ}$; $83^{\circ}$ até $98^{\circ}$ dia após o transplantio, correspondendo cada uma ao consumo médio ao longo do ciclo de 96; 153 e $114 \mathrm{~mL} \mathrm{dia}^{-1}$, respectivamente.

TABELA 4. Consumo médio de água pela cultura do crisântemo, cv. Bi Time, ao longo do ciclo de desenvolvimento, de acordo com a frequiência de irrigação.

\begin{tabular}{|c|c|c|c|}
\hline Estágios de Desenvolvimento & DAT & Freqüência de Irrigação & $\begin{array}{l}\text { Consumo Médio de Água } \\
\left(\mathrm{mL} \mathrm{dia}^{-1}\right)\end{array}$ \\
\hline \multirow{2}{*}{ Vegetativa } & \multirow{2}{*}{ até 46} & 1 vez ao dia & 55 \\
\hline & & 2 vezes ao dia & 68 \\
\hline \multirow{6}{*}{ Florescimento } & \multirow{2}{*}{47 a 58} & 1 vez ao dia & 157 \\
\hline & & 2 vezes ao dia & 206 \\
\hline & \multirow{2}{*}{59 a 70} & 1 vez ao dia & 194 \\
\hline & & 2 vezes ao dia & 211 \\
\hline & \multirow{2}{*}{71 a 79} & 1 vez ao dia & 115 \\
\hline & & 2 vezes ao dia & 93 \\
\hline \multirow{2}{*}{\multicolumn{2}{|c|}{ Consumo Médio do Ciclo }} & 1 vez ao dia & 98 \\
\hline & & 2 vezes ao dia & 113 \\
\hline
\end{tabular}

Irrigação utilizando o valor médio do consumo ao longo do ciclo será excessiva na fase vegetativa de ambas as cultivares, podendo ter como conseqüência o aumento do gasto com energia, desperdício de água, possíveis danos à planta com relação a pragas e doenças e lixiviação dos nutrientes. Já para a fase de florescimento, ocorrerá o contrário, ou seja, a cultura estará sujeita a déficit hídrico, podendo afetar a qualidade final do produto.

Observa-se que a fase de maior exigência hídrica, para ambas as cultivares, correspondeu a um período intermediário da fase de florescimento (abertura dos botões florais), entre o $55^{\circ}$ e $66^{\circ}$ DAT para a cultivar Kátia, e entre o $59^{\circ}$ e $70^{\circ}$ DAT para a Bi Time (Tabelas 2 e 3). Resultados semelhantes foram observados por PEREIRA (2002).

Nas Figuras 4 e 5, são apresentados os consumos de água pelas cultivares ao longo do ciclo em relação à evaporação do tanque Classe A. Nota-se que o consumo de água pelas plantas é crescente, atingindo ponto de demanda máxima e decrescendo, em seguida, até o ponto de colheita, para ambas as cultivares. Durante a fase vegetativa, os gráficos de barras apresentam crescimento suave, isso porque o consumo de água cresce gradativamente e, na floração, o consumo de água aumenta, decrescendo após a plena abertura das inflorescências.

Em um sistema de manejo de irrigação, a quantidade de água a ser aplicada pode ser obtida multiplicando-se os valores de evaporação do tanque Classe A pelo coeficiente relativo à fase de desenvolvimento da cultura. Para as cultivares Kátia e Bi Time, esses coeficientes são apresentados nas Figuras 4 e 5 . O uso desses valores oferece uma forma prática para fazer o manejo da irrigação da cultura do crisântemo.

Os valores de consumo relativo, encontrados neste trabalho, não apresentaram diferenças significativas para as frequiências e variedades estudadas, podendo-se adotar os coeficientes médios de consumo diário de 53; 95; 121 e $108 \mathrm{~mL}$ por vaso e de 66; 107; 100 e $82 \mathrm{~mL}$ por vaso para cada mm de evaporação do tanque Classe A, para as cultivares Kátia e Bi Time, respectivamente. Entretanto, foram superiores àqueles apresentados por PEREIRA (2002), que trabalhou com a cultura do crisântemo, cultivar White Diamond. 

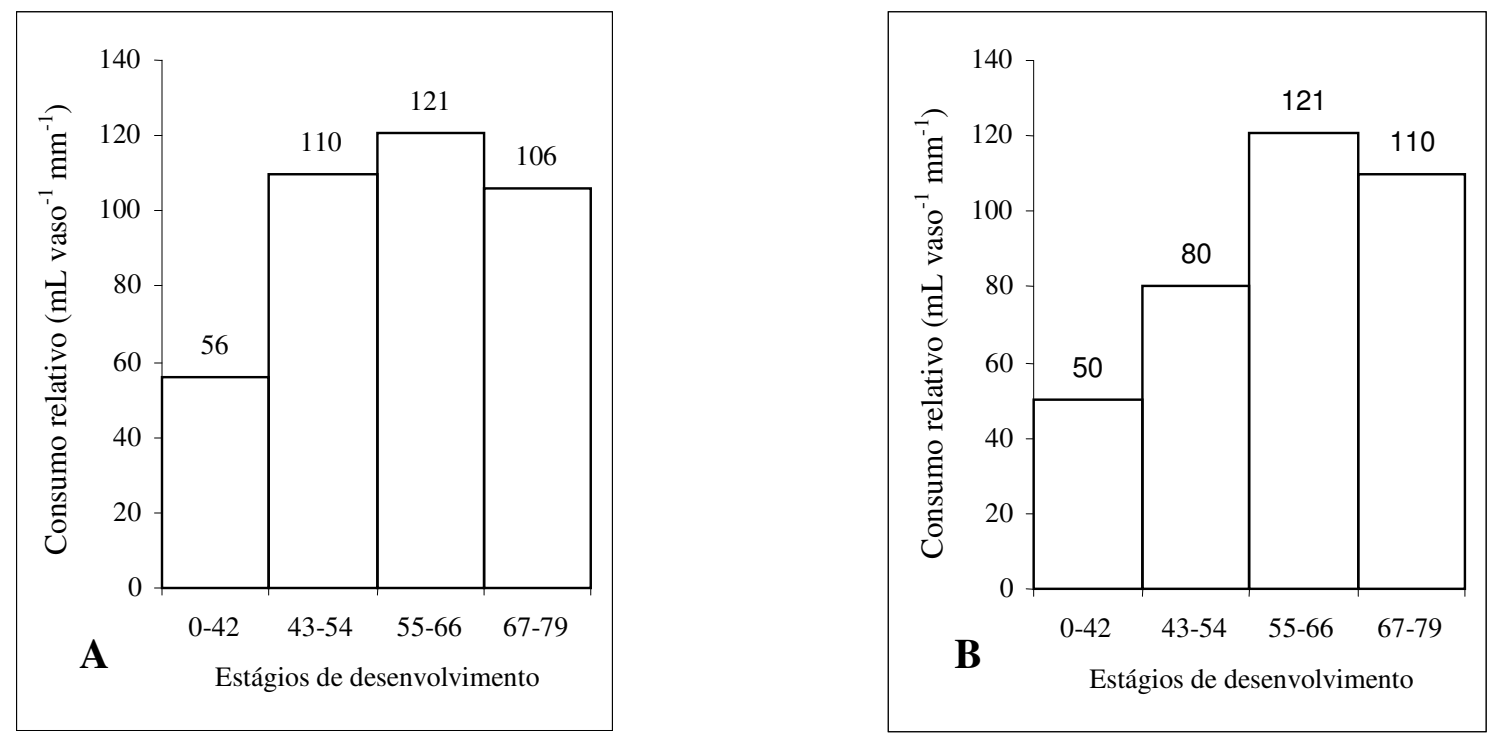

FIGURA 4. Consumo relativo de água pela cultura do crisântemo, cultivar Kátia, ao longo do ciclo de desenvolvimento, considerando a evaporação do tanque Classe A. (A) Freqüência de irrigação de uma vez ao dia. (B) Freqüência de irrigação de duas vezes ao dia.
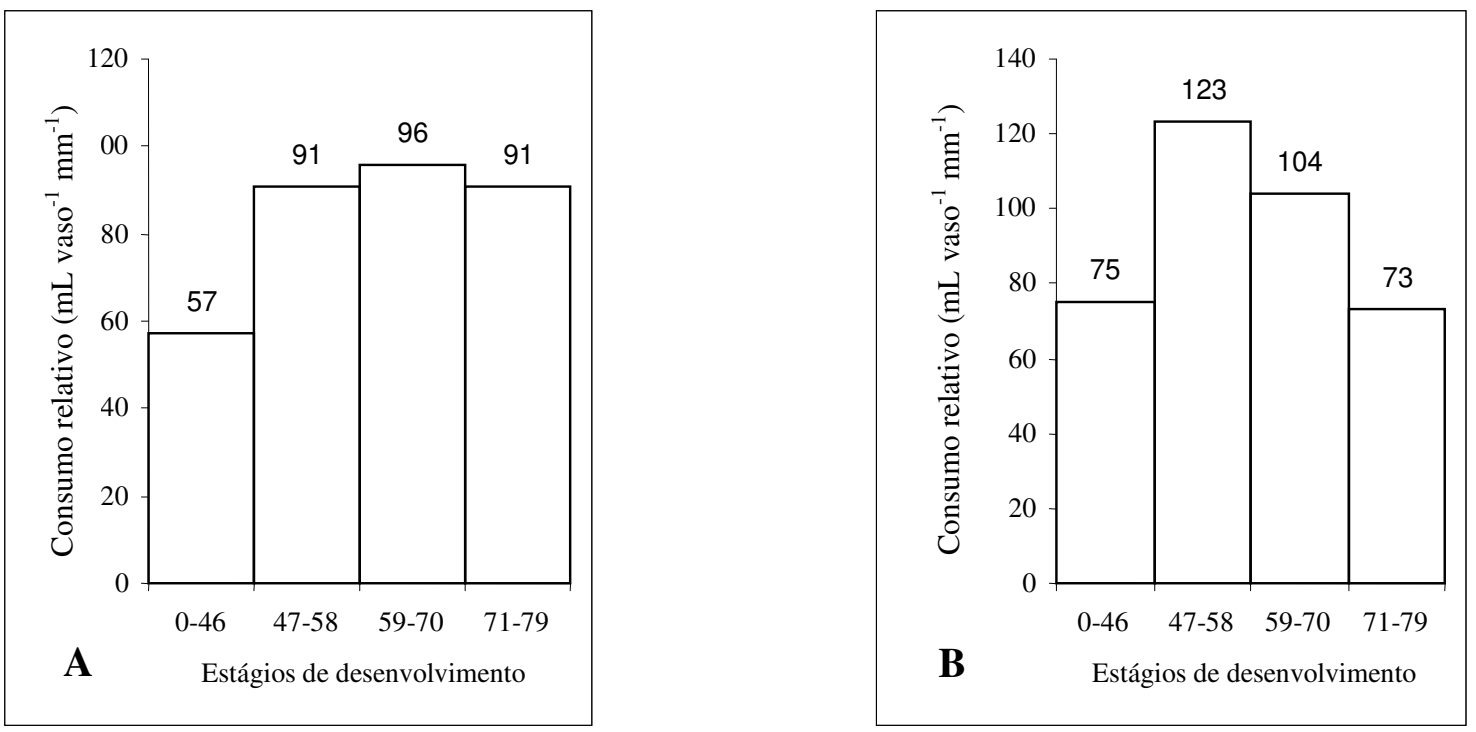

FIGURA 5. Consumo relativo de água pela cultura do crisântemo, cultivar Bi Time, ao longo do ciclo de desenvolvimento, considerando a evaporação do tanque Classe A. (A) Freqüência de irrigação de uma vez ao dia. (B) Freqüência de irrigação de duas vezes ao dia.

\section{CONCLUSÕES}

O manejo da irrigação para as cultivares Kátia e Bi Time deve ser feito de acordo com o estágio de desenvolvimento da cultura. O consumo médio de água, ao longo do ciclo, para freqüência de irrigação de uma e duas vezes ao dia, da cultivar Kátia, é de 118 e 108 mL dia ${ }^{-1}$ e, da cultivar Bi Time, é 98 e $113 \mathrm{~mL} \mathrm{dia}^{-1}$, respectivamente. Os coeficientes médios de consumo diário, para as diferentes fases, foram de 53; 95; 121 e $108 \mathrm{~mL}$ por vaso e de 66; 107; 100 e $82 \mathrm{~mL}$ por vaso para cada mm de evaporação do tanque Classe A, para as cultivares Kátia e Bi Time, respectivamente. 


\section{AGRADECIMENTOS}

À empresa Van Zanten Schoenmaker Chrysanthemum do Brasil, pela doação das mudas e pela atenção prestada na solução de nossas dúvidas.

\section{REFERÊNCIAS}

CASARINI, E. Manejo da irrigação na cultura da roseira cultivada em ambiente protegido. 2000. 66 f. Dissertação (Mestrado em Irrigação e Drenagem) - Escola Superior de Agricultura "Luiz de Queiroz", Piracicaba, 2000.

FERREIRA, D.F. SISVAR. Versão 4.3 (Build 4.1). Lavras: UFLA/DEX, 1999. 4 disquetes.

FURLAN, R.A Consumo de água pela cultura do crisântemo envasado, cultivar Puritan, sob condições de estufa. 1996. 96 f. Dissertação (Mestrado em Irrigação e Drenagem) - Escola Superior de Agricultura "Luiz de Queiroz”, Piracicaba, 1996.

GRUSZYSNKI, C. Produção de crisântemos. 2000. Disponível em:

<www.emater.tche.br/docs/artigos/crisa/crisant.htm>. Acesso em: 16 dez. 2001.

MARTINS, S.R.; FERNANDES, H.S.; ASSIS, F.N.; MENDEZ, M.E.G. Caracterização climática e manejo em ambientes protegidos: a experiência brasileira. Informe Agropecuário, Belo Horizonte, v.20, n.200/201, p.15-23, set./dez. 1999.

MOTOS, J.R; OLIVEIRA, M.J.G. de (Coords.). Produção de crisântemos em vaso. Holambra: Flortec, 1990. 34 p.

MOTOS, J.R. Crisântemo em vaso. In: IBRAFLOR. Padrão IBRAFLOR de qualidade. Campinas: 2000. p. 9-10.

PEREIRA, J.R.D. Análise dos efeitos da época de suspensão da fertirrigação e de níveis de reposição de água à cultura do crisântemo (Dendranthema grandiflora) cv. White Diamond. $2002.54 \mathrm{f}$. Dissertação (Mestrado em Irrigação e Drenagem) - Universidade Federal de Lavras, Lavras, 2002.

SILVA, W.L.C.; MAROUELLI, W.A. Manejo da irrigação em hortaliças no campo e em ambientes protegidos. In: FARIA, M.A. (Coord.). Manejo de irrigação. Lavras: UFLA/SBEA, 1998. p.311-48.

VILLA NOVA, M.S. Avaliação do desempenho do tensiômetro de bolha de ar na medida do potencial matricial de água no solo. 1991. 69 f. Dissertação (Mestrado em Irrigação e Drenagem) - Escola Superior de Agricultura “Luiz de Queiroz", Piracicaba, 1991. 